\title{
JEAN-YVES VIALLETON, Poésie dramatique et prose du monde. Le comportement des personnages dans la tragédie en France au XVII siècle
}

\section{Monica Pavesio}

\section{(2) OpenEdition}

\section{Edizione digitale}

URL: http://journals.openedition.org/studifrancesi/33101

DOI: 10.4000/studifrancesi.33101

ISSN: 2421-5856

\section{Editore}

Rosenberg \& Sellier

\section{Edizione cartacea}

Data di pubblicazione: 1 décembre 2005

Paginazione: 633-634

ISSN: 0039-2944

\section{Notizia bibliografica digitale}

Monica Pavesio, «JEAN-YVES VIALLETon, Poésie dramatique et prose du monde. Le comportement des personnages dans la tragédie en France au XVIIe siècle», Studi Francesi [Online], 147 (XLX | III) | 2005, online dal 01 novembre 2015, consultato il 18 avril 2021. URL: http://journals.openedition.org/ studifrancesi/33101; DOI: https://doi.org/10.4000/studifrancesi.33101

Questo documento è stato generato automaticamente il 18 avril 2021

\section{(c) $(1) \&$}

Studi Francesi è distribuita con Licenza Creative Commons Attribuzione - Non commerciale - Non opere derivate 4.0 Internazionale. 


\title{
JEAN-YVES VIALLETON, Poésie dramatique et prose du monde. Le comportement des personnages dans la tragédie en France au XVII siècle
}

\author{
Monica Pavesio
}

\section{NOTIZIA}

JEAN-YVES VIALLETON, Poésie dramatique et prose du monde. Le comportement des personnages dans la tragédie en France au XVII ${ }^{e}$ siècle, Paris, Champion, 2004, pp. 822.

1 Il ricco ed interessante studio di Jean-Yves Vialleton, versione riveduta e corretta della tesi di dottorato dell'autore, diretta da Georges Forestier, è il cinquantaduesimo volume della collana di Champion «Lumières Classique», diretta da Philippe Sellier.

2 Partendo dalla famosa frase di La Bruyère "Corneille et Racine peignent", l'autore annuncia nell'introduzione lo scopo del suo voluminoso studio: illustrare la pittura dei comportamenti umani e dei costumi nella tragedia classica. Le fonti utilizzate sono le tragedie, ma anche le tragicommedie, le commedie eroiche e le tragedie in musica, comprese nel periodo che va dal 1634, anno di Médéé di Corneille e dell'Hercule mourant di Rotrou, al 1697, anno di Méduse, l'ultima tragedia dell'abate Boyer.

3 La prima sezione, denominata Dramaturgie et mise en scène de soi, illustra come i trattati di comportamento forniscano delle regole, - quella di circostanza, per esempio, che comprende il luogo, il momento e l'occasione - concernenti il comportamento da tenere in determinate occasioni della vita quotidiana che permettono di rivedere questioni di capitale importanza teatrale come quella del luogo tragico, del comportamento del personaggio, del costume, della presenza del personaggio accessorio. 
4 La seconda parte - Poésie tragique et bon usage de la parole - si occupa invece del linguaggio drammatico e delle sue implicazioni con le forme e le regole del comportamento. L'autore si prefigge in questa seconda sezione di studiare il discorso dei personaggi drammatici, come elemento di comportamento.

5 Le conclusioni ottenute in queste due prime sezioni permettono all'autore di illustrare come la rappresentazione del comportamento a teatro, più che essere un riflesso dei costumi della "vita civile" e della loro evoluzione, si colleghi a problemi di ordine estetico.

6 La terza parte, intitolata Morale tragique et science du monde, si occupa di evidenziare questi problemi, soffermandosi in particolare sul ruolo che giocano le nozioni di civilité, honnêteté e bienséance sulla tragedia classica.

7 Lo studio di Vialleton si conclude illustrando come la questione della rappresentazione del comportamento nella tragedia si inscriva in una discussione più ampia, concernente lo statuto stesso della poesia del XVII secolo.

8 Il volume è corredato di una ricca bibliografia e di un indice dei nomi e delle numerose pièces analizzate. 